University of Nebraska - Lincoln

DigitalCommons@University of Nebraska - Lincoln

Faculty Publications: Department of Entomology

Entomology, Department of

1999

\title{
Dispersal of Synanthropic Diptera: Lessons from the Past and Technology for the Future
}

Carl J. Jones

University of Illinois at Urbana-Champaign

Scott A. Isard

University of Illinois at Urbana-Champaign

M. Roberto Cortinas

University of Nebraska-Lincoln, mcortinas2@unl.edu

Follow this and additional works at: https://digitalcommons.unl.edu/entomologyfacpub

Part of the Entomology Commons

Jones, Carl J.; Isard, Scott A.; and Cortinas, M. Roberto, "Dispersal of Synanthropic Diptera: Lessons from the Past and Technology for the Future" (1999). Faculty Publications: Department of Entomology. 239. https://digitalcommons.unl.edu/entomologyfacpub/239

This Article is brought to you for free and open access by the Entomology, Department of at DigitalCommons@University of Nebraska - Lincoln. It has been accepted for inclusion in Faculty Publications: Department of Entomology by an authorized administrator of DigitalCommons@University of Nebraska - Lincoln. 


\title{
Dispersal of Synanthropic Diptera: Lessons from the Past and Technology for the Future
}

\author{
CARL J. JONES, ${ }^{1}$ SCOTT A. ISARD,${ }^{2}$ AND M. ROBERTO CORTINAS ${ }^{1}$
}

\begin{abstract}
Ann. Entomol. Soc. Am. 92 (6): 829-839 (1999)
ABSTRACT The impact of aerial invasion of new habitats by dispersal of synanthropic arthropods on human society is one of the most important topics in the entomological world. A review is presented of important advances in the knowledge of dispersal of a number of dipteran species that cause damage to, or serve as vectors for diseases of, humans and associated animals. The components of aerial dispersal are delineated, and forms of dispersal are defined in the context of interactive forces that result in dispersal by synanthropic Diptera. Migratory flights by black flies are put into ecological perspective, as are the wind-borne movements of ceratopogonid vectors of viruses. Dispersal by house flies, screwworms, and stable flies are specifically addressed to trace the changes in technology used to detect and quantify aerial dispersal during the 20th century and to propose new ways to use current technology.
\end{abstract}

KEY WORDS house fly, screwworm, stable fly, aerobiology, vector-borne disease, migration

"THE ABUNDANCE AND diversity of insect life during the warmer months are sufficiently striking to attract the attention of even those not especially interested in insects. To others of a more inquiring mind the questions arise as to the means by which they came, and being here, how is it that they are able to remain." F. M. Webster spoke those words in 1903. In an address delivered at the University of Chicago and later published in Psyche (Webster, 1903), he went on to say that the 18th and 19th centuries were the time to name insects and delineate the state in which they were found. The 20th century was to be a time for learning about habitat and breaking down political boundaries to better describe the relationships of arthropods in the Americas.

This issue honors one of the most prolific students of insect evolution, C. W. Schaefer, who has helped realize Webster's prediction. The volume and depth of his work, and the quality that he brought out in the work of other scientists through his editing have had an enormous impact on the way we view both dispersion and dispersal of arthropods. Those of us who wish to contribute to the understanding of insect distribution and dispersion, yet are less taxonomically gifted than Schaefer (virtually all of us, I suspect), may take solace in studying the means by which insects disperse from one region to another. The 20th century has indeed been a time in which we have made great strides in understanding relationships within the biosphere. However, among the least studied aspects of insect dispersal are the biological and meteorological

\footnotetext{
${ }^{1}$ Departments of Veterinary Pathobiology, University of Illinois at Urbana Champaign, Urbana, IL 61802.

${ }^{2}$ Department of Geography, University of Illinois at Urbana Champaign, Urbana, IL 61802.
}

interactions that occur during dispersal, influencing the destination and success of aerial movement. Perhaps if Webster were alive today he would say that the 21 st century should be a time for understanding the drives and mechanisms that result in dispersal of biota, the processes that influence their transport, and their impact at a destination.

Here we give a brief historical discussion of studies on the dispersal of selected species of synanthropic Diptera, discuss some of the technology changes that have made these studies possible, and suggest some possible directions and uses for technology in future studies of aerial dispersal of arthropods. We use the aerobiology pathway model (Fig. 1) developed in the 1970s during the United States/International Biophysical Program in Aerobiology (Benninghoff and Edmonds 1972) as a conceptual framework. Examining a dynamic process in this fashion allows us to focus on the many factors that affect biota in each stage of the process, and to recognize the deficiencies inherent in most dispersal studies of synanthropic Diptera. The model is composed of 5 components or stages: preconditioning in a source area, takeoff/ascent, dispersion, descent/landing, and impact at the destination. Each organism that moves in the atmosphere proceeds through this sequence of stages. The division of the dispersal process in this manner facilitates the coupling of the various stages in the life cycle of aerobiota.

Diptera are the most important group of arthropods serving as vectors of diseases. Additionally, they also cause direct damage to hosts through blood loss, dermatitis, myiasis and other forms of physical trauma. The high rates of mobility of adult populations of many dipteran species, combined with the relative stability of their larval environments, create an intriguing dichotomy that has always interested scientists. Their 


\section{Aerobiology Pathway Model}

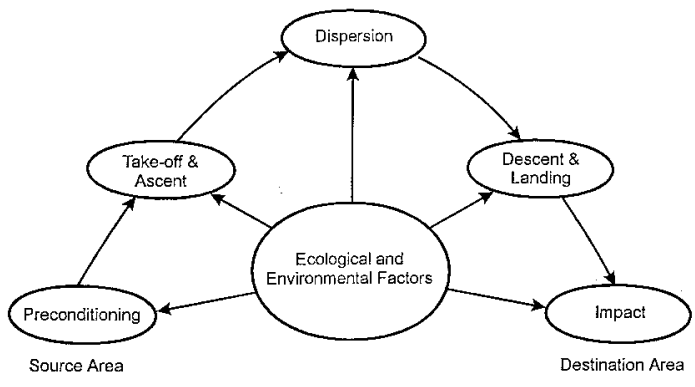

Adapted from Benninghof and Eơmonds 1972

Fig. 1. Aerobiology pathway model easily adaptable to use with synanthropic Diptera was proposed by Benninghoff and Edmonds (1972). Takeoff and ascent stage of Dipteran movement occurs after a developmental or preconditioning stage that occurs near the larval development site. Takeoff is influenced by environmental and biological factors that dictate the timing of activities resulting in flight initiation. Ascent is the period of upwardly directed flight through the surface layer of the atmosphere that carries Diptera to an altitude where strong winds or convective currents govern their movements. Horizontal transport takes place high in the planetary boundary layer and is the component that dictates flight pathways and consequently destination. Descent through the surface layer is the final stage of movement. Descent by some flying insects may be assisted by rainfall.

mobility as adults encourages constant colonization of new habitats, creating waves of expansion that may fall on either fertile or unsuitable substrates. In addition, certain physiological characteristics of Diptera make them ideal subjects for the study of dispersal. Their large size makes them generally visible even to the unaided eye, gender is easily determined for most, and blood feeding habits of many make it relatively easy to attract them. Finally, commonly mammalophilic feeding habits make them of great interest to humans so that a great deal of effort has been expended in the study of their physiology.

Rather than try to cover all the important species of Diptera in which dispersal has been studied we will limit our discussion to selected species from among the Ceratopogonidae, Calliphoridae, Simuliidae, and Muscidae. M. W. Service (1997) has written an excellent review of dispersal by Culicidae based on his presentation in the symposium "Dispersal of Hematophagous Vector and Pest Arthropods" at the 1996 Annual Meeting of the Entomological Society of America. His publication fills any need to review that critically important family in the following pages. However, our discussion is intended to view advances from a technological rather than a taxonomic perspective within the Order Diptera.

Arguments over the differences between dispersal and migration fill the entomological literature. Historically, movements of many anautogenous insect species, have been broadly divided into 2 groupings: appetitive and dispersal flights. Appetitive, or goaloriented, flights are induced by the instinct to seek nectar, a mate, a blood meal, a resting spot, an oviposition site, or other things that have a direct, immediate goal. Dispersal flights, however, are considered nongoal oriented. Wenk (1981) separates dispersal flights into migration, defined as long distance, wind-aided movement, and "true" dispersal flights which are shorter in distance, unaided, and associated with appetitive flight. Service (1997) advances a series of arguments that thoroughly convince us that mosquito movement generally is not migration in the truest sense, but encompasses other forms of dispersal. We followed the same philosophy when considering the insects discussed below, although some forms of black fly movement qualify as migration, rather than simply appetitive dispersal. In these cases, the movement falls strictly under Johnson's (1969) definition of a class II migration, in which an insect moves away from its larval development site (home range) and returns in the same season. The most compelling definitions of movement may be those used in most ecology texts and paraphrased as follows: dispersal is the sum of movement of biota which can be broken down into; migration is the periodic movement of a single individual from one habitat to another and back; immigration is the terminal movement of a single individual into a habitat, resulting in a net increase in the population in that habitat; and emigration is the movement out of a habitat, resulting in a net decrease in the population in that habitat.

From a static perspective, it may appear that migration is composed of both immigration and emigration. However, the result of each is a permanent dispersal to or from another habitat, whereas true migration results in an individual eventually returning to its original habitat. Both emigration and immigration of reproductive individuals of a species result in genetic redistribution of the subject species. Successful immigration is a precursor to an attempt at colonization of a new habitat, but does not imply successful colonization.

\section{House Flies}

General Considerations. For most of us, the ubiquitous house fly, Musca domestica L., exemplifies the term synanthropic. Greenberg (1971) in his landmark book Flies and Disease describes this species as eusynanthropic, one of a group of species that has classically adapted to utilization of human society for feeding and reproduction. Postulated to have been coprophagous originally, it has retained that trait in livestock facilities while adapting to search for food even in our cozy homes and offices. Any entomologist working with live material has probably had a house fly attempt to make his or her laboratory or office into a "musca-cafeteria." However, we do an injustice to the adaptability of the house fly when we think of it as being merely endophilic. In the tropics and in neotropical regions this species is abundant outdoors and may even show a preference toward exophilia as temperatures increase (Greenberg 1971). Cattle feedlots in the United States present the same kind of outdoor 
experience for flies, especially during the summer months.

In North America, and in most temperate regions, it is difficult for the house fly to survive the winter outdoors. Populations of adults plummet, and larval growth decreases drastically as temperatures near $0^{\circ} \mathrm{C}$. In the spring, surviving fly populations are located in tightly defined loci or are extremely scattered, depending on the habitat. The change in distribution that occurs following these circumstances results from short distance dispersal and has been the subject of hundreds of scientific and lay studies.

Selected Studies. Most studies of house fly dispersal have concentrated on dispersion, landing as measured by attraction, and impact at destination. A short survey of early and recent studies allows appropriate perspective on the changes in technology used in house fly dispersal studies during this century. Hodge (1913) found house flies resting on boat cribs as far as $9.7 \mathrm{~km}$ from shore on Lake Erie. Because there appeared to be no larval development site in the area, he assumed that they had flown there or been carried by prevailing winds. In Miles City, MT, at an elevation of $\approx 800 \mathrm{~m}$ above sea level, an enormous horse sales operation created a utopian environment for house flies and the perfect opportunity for R. R. Parker (1916) to study the spread of house flies in an "urban" environment. Releasing 387,877 laboratory reared flies stained with rosolic acid, aqueous eosin, trypan blue, acid fuchsin, or methylene green, Parker recaptured 1, 056 stained flies using a network of 91 beer and oatmeal baited traps in the city, at the horse facility, and in various other environs, including the city dump. All captured flies were killed with ether, placed on newspaper, and sprayed with ethanol to remove the dye which then colored the paper. He was able to document individual fly movement of $2.1 \mathrm{~km}$ within the city and $3.2 \mathrm{~km}$ outside the city. Driven by stimuli associated with food or oviposition sites, the house fly was almost constantly moving. Parker hypothesized that an oviposition site was merely the center for the next series of movements for this "migrating" insect. Against established dogma, he demonstrated that flies traveled both with and against the wind over these relatively modest distances.

Bishopp and Laake (1921), who colored several species of wild captured flies with chalk and baited them with packing house residues, corroborated the concept that wind direction seemingly had no effect on direction of dispersal, but emphasized that food and oviposition sites were the critical stimuli inducing dispersion. As in previous work, however, they noted that wind speed was difficult to measure, and was often inconsistent around buildings. Nevertheless, they extended the range of released house flies to 22.2 $\mathrm{km}$ altogether, $9.7 \mathrm{~km}$ in $24 \mathrm{~h}$ in rural Texas.

By the 1950s, marking technology had become more sophisticated. Quartermann and his colleagues (Quartermann et al. 1954a, b) used combinations of dyes and radioactive marking to demonstrate movement of up to $12.2 \mathrm{~km}$ in urban Savannah and $12.5 \mathrm{~km}$ in rural Georgia. They posited that the limitations of their trap layout prevented them from finding flies as far as $16 \mathrm{~km}$ downwind from the release point, at which point habitat seemed less favorable for the flies.

Micronized fluorescent dust placed on captured adults or adults reared from wild-caught larvae were used to study the overwintering sites of house flies on animal farms in England (Denholm et al. 1985). Under normal circumstances, flies released indoors stayed in the building. They found that males were more likely to relocate than females, but of the 24,000 released flies, only 2 were found as far as $1.5 \mathrm{~km}$ away. Additionally, they measured gene flow through a group of farms by studying the diffusion of a recessive marker gene that they introduced. By studying the frequency buildup of this marker gene at distal sites, they were able to determine that flies from one farm founded the population on a 2 nd farm on which overwintering success had apparently been poor. In fact, whichever farms had the earliest spring population increase served as a source for immigrants on the other farms, with founding effects shown on farms $2.5 \mathrm{~km}$ from the original source by August. Because the authors said so little about the surrounding area, we must assume that a large number of flies were exophilic during the summer months throughout the course of these experiments and most reproduction took place outdoors.

Technological Advances. It is clear that the house fly disperses widely over small distances, and the technology used to determine the process was adaptive to those distances. Much of the technology used in these studies is now obsolete because we are aware that it may statistically predispose the results to certain kinds of error. Penetrating dyes and physical handling of flies are especially eschewed in current research, but the use of micronized fluorescent powders and marker genes is still very common.

\section{Screwworms}

General Considerations. Dispersal is not just a local phenomenon among synanthropic flies. Many of the authors who studied house fly dispersal before 1930 mentioned capturing or recapturing marked Cochliomyia macellaria $\mathrm{F}$. at distances equaling or exceeding that traversed by the house fly. During the period when the earliest of these studies took place, the primary screwworm fly, Cochliomyia hominivorax (Coquillet), was taxonomically undifferentiated from the secondary screwworm fly, so it is difficult to know which species dispersed the distances indicated. The secondary screwworm is normally thought to deposit its eggs in dead and decaying flesh. The primary screwworm fly deposits its larvae on living flesh of mammals. In the latter instance, the resulting myiasis can cause severe debilitation or even death of the host. Although capable of moving as far north as South Dakota in a single season, the primary screwworm cannot successfully overwinter north of the southernmost states in the United States. Nevertheless, movement of huge distances by successive generations of screwworm adults created enormous health problems within the livestock industry until the success of the Florida 
Screwworm Eradication Program in the late 1950s. The success of the Florida program paved the way for the Southwest Screwworm Eradication Program, which also used sterile male release technology to prevent the annual spread of the flies.

Selected Studies. Although preconditioning may play a role in the dispersal of the screwworm, most studies of this fly included only dispersion and impact on landing. Mayer and Atzeni (1993) modeled the dispersal distances estimated by a number of authors for the primary screwworm fly. Their choices were limited to authors using recapture data from marked flies rather than from any flies attracted to oviposition sites. Because attraction of a fly to an animal or an animal odor mimic such as "swormlure" indicates that the flies were prepared to oviposit if hosts were available, capture of a marked fly at such a site is presumtive of an attempt at reproduction. (Swormlure, which was developed for screwworm studies and was made from chemicals generated during tissue decay to simulate an animal wound and thus attract gravid females, probably generates an additional or altogether different type of stimulus because it induces sexual behavior in both sexes and attracts young and unmated females similar to those attracted to mating sites.) However, sterile egg mass data, used by some authors to detect dispersal of primary screwworm flies after the initiation of the Southwest Screwworm Eradication Program, may combine 2 disparate stages of movement. For example, sterile males delivered as part of the screwworm eradication program may move from their release point to a mating site, followed by the movement of mated females to a host where they deposit sterile eggs. Because Mayer and Atzeni wanted to know only how far a single fly could move, they eliminated data collected by any other techniques. With this caveat, they pooled the data of Hightower et al. (1965), Hightower et al. (1968), Ahrens et al. (1976), Broce et al. (1979), Brenner (1984, 1985), and Parker and Welch (1991). As the model developed, factors that influenced dispersal distance included host abundance, trap proximity to release point, and climatic factors. The most biologically valid estimates resulted from the use of habitat type as a predictor of distance moved. According to their model, $90 \%$ of female flies would move no more than $22.1 \mathrm{~km}$, especially in relatively rich habitat. However, this does not invalidate the importance of the observations of Hightower et al. (1965) who found a single female fly $290 \mathrm{~km}$ from the release point, within 2 wk of release in relatively unfavorable habitat along the Colorado and Concho Rivers. Work by Hightower and others went a long way toward explaining how the primary screwworm fly could move north, and presumably in all directions, in waves as the spring and summer progressed. Movement into areas already infested would be very difficult to track, but must be presumed to occur. The initial barrier zone maintained by the joint United States-Mexico screwworm eradication program was set at 480-800 km. Later barriers were much smaller as millions of sterile males were dropped every week. Nevertheless, given the resounding success of this program it seems unlikely that they should be criticized for assuming such a long dispersal range.

Technological Advances. Artificial bait systems, like swormlure, are unique for almost every group of synanthropic flies. Nevertheless, it is difficult to underestimate the importance of attractant sampling techniques when examining possible long-range dispersal. The use of swormlure itself is further complicated by its stimulation of sexual behavior in both sexes (Broce et al. 1980). The mating of irradiated male flies to wild female flies results in the opportunity to use sterile egg masses in dispersal studies. Today, this technique has only limited candidates for use in dispersal studies despite its tremendous success in integrated pest management (IPM).

\section{Ceratopogonidae}

General Considerations. Health problems are more frequently brought about by the transmission of vector-borne diseases than by direct damage. The dispersal of synanthropic Diptera plays a major role in the epidemiology of many arboviruses. Ceratopogonidae are slender gnats with an almost delicate appearance. The bite of hematophagous females is often felt as a mild burning sensation, and may leave a small petechial mark at the bite site. Pest species are generally thought to be crepuscular or diurnal, and adults rarely venture far from their larval habitat. However, some of the species that serve as vectors for viral diseases of livestock, including bluetongue virus (BTV), are nocturnal, which increases their ability to use air currents in their dispersal because winds normally increase after crepuscular periods. Sellers (1980) postulated that 18 of 24 BTV outbreaks in Cyprus could be explained by air-borne penetration of infected vectors into disease-free zones.

Selected Studies. Although incomplete in many ways, the saga of ceratopogonid dispersal includes attempts to study 4 of the 5 elements of aerial dispersal, not clearly including studies of landing. Braverman and Chechik (1993) examined BTV and Akabane virus outbreaks in Israel that occurred between 1964 and 1988. They postulated that outbreaks may have been the result of infected Culicoides imicola Kieffer dispersal from the delta created by the Tigris and Euphrates Rivers as they flow into the Persian Gulf, aided by the prevailing winds from the Persian trough air stream. During the summer months when BTV reached the previously disease-free Israeli livestock, appropriate conditions for night insect transport (wind speed, temperature and relative humidity) were suitable at elevations of $1.0-1.5 \mathrm{~km} \mathrm{3-15}$ times per month. Transmission of Akabane virus, in 1969, by wind-borne $C$. imicola could have been accomplished during $20 \mathrm{~d}$ in a single month with the help of the Red Sea trough from North Africa. Sampling during the occurrence of the Persian trough, with a net-rigged Piper Super Cub at air speeds between 69 and $76 \mathrm{kph}$, Braverman and Greenstone (1996) collected Ceratopogonidae at $50 \mathrm{~m}$, and unidentified Diptera between 30 and 1,000 $\mathrm{m}$ from the surface. Even at these low air 
speeds, insects were generally crushed and difficult to identify.

A different mode of vector dispersal has been documented on the eastern Australian coastal plains, where evening wind cells develop from the northeast, and windspeed declines as cells contract to the coast. In this region, C. brevitarsis Kieffer, which flies when winds are $<8 \mathrm{kph}$, serves as the vector for Akabane virus. Caught in light traps at elevations of $6 \mathrm{~m}$, these insects are behaviorally capable of being caught by prevailing night winds and transported hundreds of kilometers (Murray 1995). Captures of relatively young gnats outside the zone in which they can overwinter is a fairly common occurrence, and of little concern except to entomologists. However, collections of $C$. brevitarsis outside its overwintering zone and correlation of these captures with epizootics of Akabane virus led to examination of the factors that might serve as the proximal factors in transmission. Gnats acquired virus at endemic sites north of the epizootic sites, and when conditions permitted a higher than normal survival rate (Akabane is generally transmitted during the 3rd gonotrophic cycle.) high numbers of infected vectors were transported by winds passing over virus-free, C. brevitarsis-free, zones.

Technological Advances. Ceratopogonids are flies clearly capable of being carried by prevailing winds, possibly with little effort of their own. The use of aircraft to capture arthropods at various altitudes has been accomplished previously (Glick 1939). However, it is important to remember how delicate Culicoides are, and how difficult it is to navigate slow flying aircraft, especially at low altitudes at night. In these instances, it was the presence of arboviruses that helped the entomologists with their conclusions, not identification of specific arthropods, which they might have gotten from landing data. For many arboviruses, strain identification will be possible in the near future, making viral source information even more specific and valuable.

\section{The Stable Fly}

General Considerations. The stable fly, Stomoxys calcitrans (L.), is a muscoid Dipteran that is frequently mistaken for a house fly by many people. The fact that both sexes take their blood meals without the benefit of anesthetic allows most people to quickly realize that they have made a misidentification. Regional names include biting house fly as well as lawnmower fly, canoe fly, dog fly, and others even more colorful, if less printable. This nearly ubiquitous fly has been collected in a wide variety of nonagricultural habitats. In Krafsur's study (1993) of limited stable fly populations in the midwestern United States, gene flow in the stable fly was so high that it compensated for differences in selection among habitats, a finding later supported by a study by Szalanski et al. (1996).

Dispersal of the stable fly has been of interest in both the livestock and tourist industries in North America. Campbell and his colleagues (Campbell et al.
1977, Berry et al. 1983 and Wieman et al. 1992) have demonstrated economic damage and thresholds for cattle in the Midwest. Other regions generally use their data to set appropriate standards for stable fly population control at livestock facilities. However, it takes far fewer flies to elicit a negative response from humans than from cattle. Stable flies disrupt events from the backyard to the beach, and although their presence is most often blamed on local livestock producers, larval development frequently takes place in improperly composted garden or yard waste. Large numbers of stable flies invading the Gulf Coast of Florida at discrete intervals during the late summers and falls during the 1930s and 1940s stimulated many studies of stable fly oviposition and dispersal behavior along the shoreline (King and Lenert 1936, Simmons and Dove 1941, Williams et al. 1980). There are other sites where stable flies have been a frequent problem for tourists, including the shores of Lake Superior, Lake Michigan, and coastal New Jersey. As a result, there is probably more known about the dispersal of these flies near beaches than in the agricultural areas where many are thought to originate.

Selected Studies. Ascent, landing, and impact at landing have been studied with this species. In addition, conjectures about dispersing and preconditioning are based on reasonable preliminary data. Capable of flying up to $29 \mathrm{~km}$ in $24 \mathrm{~h}$ on a flight mill (Bailey et al. 1973), radioactively marked flies have been found $>8 \mathrm{~km}$ from their release point within $4 \mathrm{~h}$ of release (Eddy et al. 1962). Sticky trap data show that stable flies stay close to the ground during short-distance dispersal activities, probably rarely going higher than $1.8 \mathrm{~m}$ from the ground when traveling to feeding sites, oviposition sites, and nighttime resting sites (Gersabeck and Merritt 1983).

Although odors are used by stable flies for locating hosts within close proximity and in the upwind direction (Warnes and Finlayson 1985, Hogsette 1993), the use of olfactory cues is not efficient for orientation during downwind movement. Unless other mechanisms are in effect, the accumulation of stable flies and other insects at coastlines after long-distance downwind aerial dispersal requires a sensory mechanism that can detect either reflected shortwave or emitted infrared radiation from the warm, light-colored sand, blue water, or warm-blooded organisms at coastlines. Laboratory studies have shown that stable flies are positively phototaxic to low-intensity light of a blueviolet composition $(420 \mathrm{~m} \mu)$ but have a negligible response to infrared wavelengths $(>700 \mathrm{~m} \mu)$ when white light is available (Waldbillig 1968). How this strong blue phototaxis induces flies to accumulate along large bodies of water and allows flies to locate watercraft and structures surrounded by water during daylight is not clear. In addition, the reproductive significance of fly movement to coastlines is questionable. Hogsette and Ruff (1985) suggest that the stable flies on beaches are victims of circumstances and have arrived at a location where successful reproduction is unlikely. This situation is common among migratory insects especially when aerial movement is associated 
with strong atmospheric motion systems (Johnson 1969). Although food may be plentiful for stable flies near watering holes for game or domestic animals, it is far less available near the large bodies of water to which their attraction is proven.

Two weather patterns that may result in inundation of Florida beaches by stable flies have been described by Hogsette and Ruff (1985) and Hogsette et al. (1987). The 1st occurs when an anticyclone is west of the beaches, largescale offshore winds over northwest Florida may draw relatively small numbers of flies from inland livestock operations as long as they blow. In the 2nd example, much higher numbers of flies, as many as 16 times the previous level (Williams 1973), can be found on the beaches after a cold front in late summer and early autumn. After such fronts, isozyme analysis of beach populations has sometimes shown the presence of rare alleles not found in other Florida populations of flies (Jones et al. 1991).

Hogsette and Ruff (1985) used Alsynite panel (visual attractant) traps to capture wild flies $>225 \mathrm{~km}$ from their marking site after the passage of a cold front. Additionally, there are indications that stable flies can move great distances with convective rainstorms in the Midwest (Jones et al. 1998). This phenomenon has been reported previously in Diptera (Taylor 1974, Murray 1995), and it may be part of the mechanism that the stable fly uses in annual waves of dispersal in the spring.

Technological Advances. The stable fly presents a unique opportunity to study aerial dispersal by arthropods. The physiology of the flies is well known: bloodmeals serve as the primary source of protein and nectar feeding probably provides at least part of the energy needed for flight although it may also interfere with blood feeding under some circumstances (Jones et al. 1985, 1991). The use of lightweight truck mounted traps (Jones et al. 1998) and remote piloted aircraft which can gather weather data (Shields 1999) permit capture of intact flies for the analyses described below.

The age of a stable fly can be determined by measuring the amount of pteridine present in the eyes (Mail et al. 1983, Lehane and Mail 1985, Lehane et al. 1986). Pteridine accumulation begins after eclosion when flies are exposed to light and the accumulation rate is temperature dependent. Scholl (1980) developed a refined physiological age grading system specifically for stable flies. Physiological age-grading can be used to determine the feeding rate of stable flies populations (Chia et al. 1981), because follicular growth may be directly correlated with the volume of blood ingested in all blood-meals combined. Buschman and Patterson (1981) found that stable fly females mated about halfway through their normal gonotrophic cycle when blood meal sources were readily available. Together, the results from chronological and physiological age grading procedures provide an estimate of the number of blood meals taken by a fly and a basis for making inferences about the fly's prior activities. For example, a nulliparous fly in an early stage of ovarian development and a chronological age of $10 \mathrm{~d}$, taken near a feedlot, is most likely to be a recent immigrant. A nulliparous fly of the same age with completed ovarian development taken several kilometers from a feedlot is probably an emigrant, but certainly dispersing. Jones et al. (1998) used these 2 techniques to show that flies caught in truck-mounted traps 3-8 $\mathrm{km}$ from the nearest livestock facility were older than flies of the same physiological age captured near livestock facilities. These flies apparently emigrated before taking sufficient blood meals for reproduction. Whether they would return to complete their reproductive cycle is unknown. Flies digest blood within 12-24 h of ingestion, so that the absence of blood in the gut provides a convenient indicator that a fly has not taken a blood meal for at least $12 \mathrm{~h}$. The analysis of the blood in the gut of a fly provides an additional measure of time since feeding and can be used to identify their last host species. Nectar may also play a role in determining dispersal status of stable flies.

\section{Black Flies}

General Considerations. Although all black flies are nectar feeders, females of most species need blood for oviposition. Because these females are pests and some transmit human and animal blood-borne diseases, epidemiological studies must include efforts to elucidate simuliid movements to understand the fly's spatial and temporal role as a disease vector. Some blood-feeding female black flies are long-distance fliers. Much of the movement described in the literature can be considered true migration because newly emerged adults move from larval development sites to feeding sites and back to larval development sites for oviposition. Before the completion of dam projects on the Danube River during the 1950s, Simulium colombaschense F. were known for their migratory prowess. When climatic conditions were favorable, millions of females would migrate from their emergence sites to locations 250-300 km away, where they would harass humans and livestock. After feeding, they would return to their oviposition sites on the Danube (Baranov 1936). S. arcticum Malloch, a serious pest of livestock in Canada, may traverse $>200 \mathrm{~km}$ from their emergence sites to feed on cattle (Fredeen 1969). This species is considered a migrant because the female adults eclose and oviposit in approximately the same site (Shemanchuk 1987).

The most extensively studied simuliid dispersal characteristics are those of the $S$. damnosum (Theobald) complex of Western Africa. This species serves as the vector for river blindness, human onchocerciasis, which is caused by infection with the filarial nematode Onchocerca volvulus (Duke 1990). However, the S. damnosum migration may be different from the black fly migrations listed above. Instead of individual females dispersing and returning to the emergence sites, $S$. damnosum females may be population migrants, because the offspring emerge at a different site from their mother's emergence site, but 
return to oviposit in the region of their mother's emergence.

Selected Studies. In the extensive discussion that follows, all 5 elements of aerial dispersal are discussed for 1 species. The importance of river blindness cannot be overemphasized as a factor in permitting and even requiring the complexity of the investigations described below and elsewhere.

Three types of dispersal have been characterized for S. damnosum in West Africa (Wenk 1981). Linear dispersal resulting in immigration occurs along savanna rivers bordered by gallery forests, and permits the flies to access permanent larval development sites during the dry season. In the wet season, linear dispersal allows the emigrating flies to disperse along the rivers and extend the larval development zone. Radial dispersal, evident in the savanna during the rainy season and in the forests throughout the year, is emigration, characterized by appetitive movement for blood meals along both rivers and small streams, and also from clumps of vegetation to other clumps. This form of dispersal may cover vast distances, potentially being the 1st long distance flight made by the postemergent adult female. "Differential dispersal" is demonstrated by $S$. damnosum females that have never oviposited. These females fly away from larval development sites into inland regions, whereas females that have oviposited remain close to the river banks, increasing the risk of onchocerciasis infection along rivers and streams (Wenk 1981).

\section{Annual Invasions in OCP Areas}

In February 1975, the World Health Organization (WHO) began the Onchocerciasis Control Program (OCP) in the Volta River Basin to decrease the morbidity of onchocerciasis in the human population (Garms et al. 1979). After initial success with aerial larviciding of development sites, S. damnosum s.l. females began to reappear in the southwestern and southern regions of the OCP area. Surveys of larval development sites did not identify treatment failures that could account for the numbers of adults observed. Upon closer examination, investigators discovered that the invading females were of the savanna subspecies of S. damnosum s.l., of which a high proportion contained infective $O$. volvulus, suggesting that these flies had reached at least the 3rd gonotrophic cycle (Garms et al. 1979).

Investigators postulated that the flies were invading the previously treated regions of the OCP. Based on the location and time of capture, it was assumed that the flies must have dispersed $300-500 \mathrm{~km}$ in $4-5 \mathrm{wk}$ (Garms et al. 1979, Johnson and Johnson 1994). Later, Cheke et al. (1990a) corroborated the previous estimates of the longevity of $S$. damnosum sensu stricto populations by means of measuring pteridine concentrations of the head. Their estimates of $27 \mathrm{~d}$ longevity for a female $S$. damnosum s.s. correlated with previous estimates based on follicular status and further strengthened the argument that older parous populations could have migrated extremely long distances in
4 wk. Similar conclusions were reached for S. sirbanum, when pteridine concentration measurements in populations invading treated regions of Mali revealed they were $\approx 29 \mathrm{~d}$ old (Cheke et al. 1990b).

Investigators now recognize the invasions as annual occurrences, timed with the onset of the wet season when the intertropical front associated with the Intertropical Convergence Zone (ITCZ) passes over the OCP area in a northerly direction (Garms et al. 1979). The direction of the invasions, which was demonstrated by cessation of immigration after rivers were larvicided southwest of areas being reinvaded, is from southwest to northeast and with the prevailing monsoon winds associated with the ITCZ (Garms et al. 1979). The confirmation that the ITCZ is the likely vehicle for long-distance migration was the end of the wet season observations of black fly movement into areas southwest of the untreated larval development sites (Crosskey 1990).

The annual invasions occur in waves as a result of the simultaneous appearance of flies over a wide area. Their onsets are marked by a sudden sharp increase in daily catches and followed by increased biting rates (Garms et al. 1979). Previous researchers discounted the possibility that the peaks were the result of emergence because of the old age of the flies. However, recent modeling by Johnson and Johnson (1994) indicates that the simultaneity could be the result of simultaneous emergence or take-off, with convergent winds serving to concentrate airborne flies.

When monsoon air masses advance, low altitude convergence occurs, resulting in the concentration of insects at the front. Locusts have been observed ascending the sloping interface along the monsoon air mass when the front is stationary. Eventually, a single linear swarm synchronized with the front develops (Sayer 1962). However, concrete evidence that black flies exhibit the same type of convergence is lacking. One reason could be that although many flies may be involved, as demonstrated at downwind oviposition sites by large numbers of daily catches, their distribution within the convergence zone may be very broad and their density low, and thus normal trapping procedures may not be effective. Additionally, because these zones occur as waves during the season, there exists a temporal distribution of a low density zone, and normal trapping techniques would have to cue in on the convergence event to achieve good catches.

Garms and Walsh (1987) have provided an interpretation of the ways in which trivial behaviors result in migration by $S$. damnosum females. After emergence, the adult female immediately takes sugar and mates. Then, it makes a programmed appetitive flight that can be wind-assisted to take its 1st blood meal. This flight, measuring up to $20 \mathrm{~km}$, terminates with the acquisition of a blood meal during daylight. After excreting the aqueous portion of the blood meal, the female exits the surface boundary layer to begin a downwind flight. The black fly may make several such flights, consuming nectar before each, during completion of the gonotrophic cycle. As the cycle nears 
completion, the migratory drive decreases and the fly enters the surface boundary layer. After resting, the female makes an appetitive flight to oviposit, which occurs in the late afternoon, followed by an overnight resting period in the tree canopy. The next morning, the female takes another blood meal and continues further flights until death.

Several factors have been correlated with long-distance migration in the simuliids. Availability of hosts and feeding preference seem to be important determinants. Shemanchuk (1987) postulates that S. arcticum migrates long distances because of the coevolution of the fly with the native ungulates whose populations were dispersed in the landscape. By using the wind, the females could disperse over vast distances and increase the probability of acquiring the blood meal required for oviposition. Hence, as one would expect, migration became closely associated with the fitness of the species. This conjecture may partially explain why some blood-feeding simuliids, such as the savanna cytospecies of S. damnosum s.l., disperse large distances.

The sometimes ephemeral nature of the habitat and the availability of larval development sites may also be important determinants of dispersal. The West African savanna, much like any other grassland ecosystem, has wider variations in temperature, precipitation, and relative humidity than the neighboring tropical forests. All but the largest rivers of the west African savanna tend to dry up during the dry season, making most larval development sites temporary, unlike the tropical forests which have recurrent precipitation, constant humidity, and stable larval development sites. Southwood (1962) explained that as a habitat becomes more stable for a particular species, there is decreased likelihood that the species will travel far from it. Garms et al. (1979) point out that "The savanna cytospecies which are subjected to a markedly seasonal climate should be migratory while their forest siblings, inhabiting a much more constant environment, are not." Cooter (1983) demonstrated no physiologic differences in flight capability among the longdistance simuliids of the savanna and the localized simuliids of the forests. Differences in behavior are most likely correlated with the habitat stability.

An important factor required for long-distance migration, however, is accessibility to suitable winds in a favorable direction. Drake and Farrow (1988) state that "Long distance migration in a particular region is an adaptation to both the seasonal variations of habitat favorability in the region and the availability of winds suitable for transporting migrants in the required directions."

Although the literature describes some general weather patterns that are associated with black fly migration in several parts of the world, and we have a general understanding of how some black flies migrate, we do not fully understand the interactions between the fly and the environment. Are black flies reacting to certain abiotic stimuli, such as light intensity, humidity gradients, atmospheric pressure, or electrical activity to stimulate initiation or termination of long-distance flight in the surface boundary layer? Or are the mechanisms that dictate flight activity, such as rainfall or wind shear, causing exit from the surface boundary layer or strong ascending air currents causing ascent, outside the control of the insect? Intrinsic factors are likely to be as important. Perhaps an important reason for terminating long-distance movement is carbohydrate limitation - just because the fly is being wind-assisted does not mean it is not using its wings. Also, it is very likely that the completion of the gonotrophic cycle plays a major role in leaving windassisted flight. Most likely, however, is that the observed migratory phenomena result from an interaction of intrinsic and extrinsic factors.

We still do not know at what time of day migratory flight occurs, where in the atmosphere the convergence zones occur, and how the flies are distributed within the convergence zone or within the surface boundary layer. Although S. damnosum appears to be a crepuscular insect, nocturnal migration should be considered. The absence of solar radiation and decreased predatory pressure could make migration during the evening very advantageous. The lower atmosphere is stable at dusk and there are no vertical air motions, and nighttime flight may allow for further distances to be covered and some navigation (Drake and Farrow 1988). Additionally, a property of land areas subject to monsoon and trade winds is the nighttime acceleration of winds located a few hundred meters above the land surface, and so long-distance flights in western Africa might be more favorable during the night (Garms and Walsh 1987). Both attractant light trapping and nonattractant trapping techniques have indicated that species of the S. damnosum complex, besides being crepuscular, are active at night (Service 1981, Garms and Walsh 1987).

\section{New Research Perspectives}

Knowledge of the biological and meteorological factors that influence synanthropic arthropod dispersal lags behind that obtained for many other aerobiota, especially those of agronomic importance such as bollworm and corn earworm moths in North America (Wolf et al. 1990, 1994; Westbrook and Wolf 1998) and locusts and grasshoppers in Africa (Riley 1975, Riley and Reynolds 1979). Part of the reason for this lag is that the newest biological and meteorological technologies have not yet been used for synanthropic arthropod research. For example, we have the technology to identify, via polymerase chain reaction or other molecular identification techniques, the remains of recently crushed insects, but there has been no attempt to use them for synanthropic arthropod dispersal. Two unique radar systems now have the capability to remotely detect synanthropic Diptera and other aerobiota: insect monitoring radars (IMRs) and doppler weather radars (e.g., NEXRAD). Data from IMRs can provide information about the speed and direction of aerial movement, the altitude of flight, the size of the aerobiota, and allow separation of birds, insects, and other aerobiota into broad taxonomic 
groups (Riley 1992, Drake 1993). IMRs are sampling devices because they can measure dispersal only in a small conical volume of air above the radar. They are highly automated and can be configured to disseminate their data rapidly across the computer network. In contrast, WSR-88 d (NEXTRAD) doppler weather radars have the capability to detect concentrations of synanthropic Diptera at a range of $100 \mathrm{~s}$ of $\mathrm{km}$. At altitudes below $3 \mathrm{~km}$, aerobiota are the principal source of "clear-air echo" and are used routinely to estimate wind speed and direction. Radar coverage within the lower atmosphere extends sufficiently far to allow these weather radars to be used as aerial surveillance tools for insect dispersal. With more than 100 installations of WSR-88D in the United States, clouds of aerobiota could be monitored as they move across North America. Used in combination with existing aerial collection techniques (Greenstone et al. 1991, Hollinger et al. 1991), these new technologies could unravel many aspects of insect dispersal, including the biological and meteorological interactions that occur during dispersal that influence the destination and success of aerial movement. A major problem with bringing any of these new techniques to bear on synanthropic arthropod dispersal is the high cost of the technology. These are all relatively expensive ways of solving questions that have relatively small economic importance in the United States without the imminent threat of disease transmission to a substantial fraction of the indigenous population. However, continued concern over the possible impacts of global warming on arthropod dispersal and invasion, coupled with increasing concerns over arthropod transmission of new and reemerging infectious disease, may give new impetus to funding in this arena. Whatever the difficulties that arise, technological advances continue to make studies of dipteran dispersal productive and produce exciting ways to unravel the secrets of aerobiota.

\section{Acknowledgments}

Jill Windy and Kelly Bollinger cheerfully provided many hours of library time in support of this project. Uriel Kitron, Jerry Hogsette, Richard Weinzierl, and 2 anonymous reviewers provided insightful comments on an early draft of this manuscript.

\section{References Cited}

Ahrens, E. H., H. C. Hofmann, J. L. Goodenough, and H. D. Peterson. 1976. A field comparison of two strains of sterilized screwworms flies. J. Med. Entomol. 12: 691-694.

Bailey, D. L., T. L. Whitfield, and B. J. Smittle. 1973. Flight and dispersal of the stable fly. J. Econ. Entomol. 66: 410411.

Baranov, N. 1936. Studien an pathogenen und parasitischen Insekten. IV. Simulium (Danubiosimulium) columbaczense Schonb en Yougoslavie. Inst. Hyg. Schule Volksgesund. Zagreb 36.

Benninghoff, W. S. and R. L. Edmonds [eds.]. 1972. Ecological systems approaches to aerobiology I. Identification of component elements and their functional rela- tionships. US/IBP Aerobiology Program Handbook Number 2. University of Michigan, Ann Arbor.

Berry, I. L., D. A. Stage, and J. B. Campbell. 1983. Populations and economic impacts of stable flies on cattle. Am. Soc. Agric. Eng. 26: 873-877.

Bishopp, F. C., and L. W. Laake. 1921. Dispersion of flies by flight. J. Agric. Res. 21: 729-766.

Braverman, Y., and F. Chechik. 1993. Air streams and their possible potential for the introduction of Culicoides (Diptera: Ceratopogonidae) borne animal diseases to Israel. Isr. J. Vet. Med. 48: 1-9.

Braverman, Y., and M. H. Greenstone. 1996. Aircraft altitudinal sampling for Culicoides (Diptera: Ceratopogonidae) during the period of the Persian trough air stream in the eastern Mediterranean area. Isr. J. Vet. Med. $51(2): 69-73$.

Brenner, R. J. 1984. Dispersal, mating and oviposition of the screwworm (Diptera: Calliphoridae) in southern Mexico. Ann. Entomol. Soc. Am. 77: 779-788.

Brenner, R. J. 1985. Distribution of screwworms (Diptera: Calliphoridae) relative to land use and topography in the humid tropics of southern Mexico. Ann. Entomol. Soc. Am. 78: 433-439.

Broce, A. B. 1980. Sexual behavior of screwworm flies stimulated by Swormlure-2. Ann. Entomol. Soc. Am. 73: 386389.

Broce, A. B., J. L. Goodenough and J. W. Snow. 1979. Recovery of screwworm flies released at various distances and directions of the attractant Swormlure-2. Environ. Entomol. 8: 824-828.

Buschman, L. L., and R. S. Patterson. 1981. Assembly, mating and thermoregulating behavior of stable flies under field conditions. Environ. Entomol. 10: 16-21.

Campbell, J. B., R. G. White, J. E. Wright, R. Crookshank, and D. C. Clanton. 1977. Effects of stable flies on weight gains and feed efficiency of calves on growing or finishing rations. J. Econ. Entomol. 70: 592-594.

Cheke, R. A., M. Dutton, H.S.K. Avissey, and M. J. Lehane. 1990a. Increase with the age and fly size of pteridine concentrations in different members of the Simulium damnosum species complex, pp. 307-314. In Proceedings of the Symposium on Onchocerciasis, Leiden, The Netherlands. Acta Leidensia, Leiden, The Netherlands,

Cheke, R. A., M. A. Howe, M. J. Lehane, A. L. Millest, T. Kone, and R.H.A. Baker. 1990b. Discussion. Philos. Trans. Royal Soc. Lond. B 328: 748-749.

Chia, L. S., J. A. Baxter, and P. E. Morrison. 1981. Quantitative relationship between ingested blood and follicular growth in the stable fly, Stomoxys calcitrans. Can. J. Zool. 60: 1917-1921.

Cooter, R. J. 1983. Studies on the flight of black-flies (Diptera: Simuliidae): 2. Flight performance of three cytospecies in the complex of Simulium damnosum. Bull. Entomol. Res. 73: 275-288.

Crosskey, R. W. 1990. The natural history of blackflies. Wiley, Chichester.

Denholm, I., R. M. Sawicki, and A. W. Farnham. 1985. Factors affecting resistance to insecticides in house-flies, Musca domestica L. (Diptera: Muscidae). IV. The population biology of flies on animal farms in south-eastern England and its implications for the management of resistance. Bull. Entomol. Res. 75: 143-158.

Drake, V. A., and R. A. Farrow. 1988. The influence of atmospheric structure and motions on insect migration. Annu. Rev. Entomol. 33: 183-210.

Drake, V. A. 1993. Insect monitoring radar: a new source of information for migration research and operational pest forecasting, pp. 452-455. In S. A. Corey, D. J. Dall, and 
W. M. Milne [eds.], Pest control and sustainable agriculture. CSIRO, Melbourne, Australia.

Duke, B.O.L. 1990. Human onchocerciasis-an overview of the disease, pp. 9-24. In Proceedings of the Symposium on Onchocerciasis, Leiden, The Netherlands. Acta Leidensia, Leiden, The Netherlands.

Eddy, G. W., A. R. Roth, and F. W. Plapp, Jr. 1962. Studies of the flight habits of some marked insects. J. Econ. Entomol. 55: 603-607.

Fredeen, F.J.H. 1969. Outbreaks of the black fly Simulium arcticum Malloch in Alberta. Quaest. Entomol. 5: 341-372.

Garms, R., J. F. Walsh, and J. B. Davies. 1979. Studies on the reinvasion of the Onchocerciasis Control Programme in the Volta River Basin by Simulium damnosum s.l. with emphasis on the south-western areas. Tropmed. Parasitol. 30: 345-362.

Garms, R., and J. F. Walsh. 1987. The migration and dispersal of black flies: Simulium damnosum s.l, the main vector of human onchocerciasis, pp. 201-214. In Ke Chung Kim and Richard W. Merritt [eds.], Black flies: ecology, population management, and annotated world list. Pennsylvania State University, University Park, PA.

Gersabeck, E. F., and R. W. Merritt. 1983. Vertical and temporal aspects of Alsynite panel sampling for adult Stomoxys calcitrans (L.) (Diptera: Muscidae). Fla. Entomol. 66: 222-227.

Glick, P. A. 1939. The distribution of insects, spiders, and mites in the air. U.S. Dep. Agric. Tech. Bull. 673.

Greenberg, B. 1971. Flies and disease, vol. I ecology, classification and biotic associations. Princeton University Press, Princeton, NJ.

Greenstone, M. H., R. R. Eaton, and C. E. Morgan. 1991. Sampling aerially dispersing arthropods: a high-volume, inexpensive, automobile- and aircraft-borne system. J. Econ. Entomol. 84: 1717-1724.

Hightower, B. G., A. L. Adams, and D. A. Alley. 1965. Dispersal of released irradiated laboratory-reared screwworm flies. J. Econ. Entomol. 56: 798-802.

Hightower, B. G., D. A. Alley and J. C. Eddie. 1968. Observations on the effects of releasing sterile screwworm flies in northern Veracruz, Mexico. Folia Entomol. Mex. 17: $1-16$.

Hodge, C. F. 1913. The distance house-flies, blue-bottles and stable flies may travel over water. Science (Wash. D.C.) 37: 512-513.

Hogsette, J. A. 1993. The influence of poultry operations on the urban fly problem in the eastern United States, pp. 17-24. In G. D. Thomas and S. R. Skoda [eds.], Rural flies in the urban Environment? North Cent. Reg. Res. 335.

Hogsette. J. A., and J. P. Ruff. 1985. Stable fly (Diptera: Muscidae) migration in northwest Florida. Environ. Entomol. 14: $170-175$

Hogsette, J. A., J. P. Ruff, and C. J. Jones. 1987. Stable fly biology and control in northwest Florida. J. Agric. Entomol. 4: 1-11.

Hollinger, S. E., K. R. Sivier, S. A. Isard, and M. E. Irwin. 1991. A helicopter-borne isokinetic aerial insect sampler. J. Econ. Entomol. 84: 476-483.

Johnson, C. G. 1969. Migration and dispersal of insect by flight. Methuen, London.

Johnson, C. G., and R.P.C. Johnson. 1994. Computer modelling of the migration of Simulium damnosum sensu lato (Diptera: Simuliidae) across the Onchocerciasis Control Programme (OCP) area of West Africa. Bull. Entomol. Res. 84: 343-353.

Jones, C. J., J. A. Hogsette, R. B. Patterson, and D. E. Milne. 1985. Effects of natural saccharide and pollen extract feeding on stable fly (Diptera: Muscidae) longevity. Environ. Entomol. 14: 223-227.

Jones, C. J., J. A. Hogsette, R. B. Patterson, D. Milne., G. D. Propp, J. F. Milio, L. G. Rickard, and J. P. Ruff. 1991. Origin of stable flies (Diptera: Muscidae) on west Florida beaches: electrophoretic analysis of dispersal. J. Med. Entomol. 28: 787-795.

Jones, C. J., J. A. Hogsette, S. A. Isard, Y.-J. Guo, G. Greene, and A. Broce. 1998. Using phenology to detect dispersal of stable flies in western Kansas, pp. 348-351. In Proceedings of the American Meteorological Society, 13th Conference on Biometeorology and Aerobiology. American Meteorological Society, Albuquerque, NM.

King, W. V., and L. G. Lenert. 1936. Outbreaks of Stomoxys calcitrans (L.) (“dog flies") along Florida's northwest coast. Fla. Entomol. 19: 33-39.

Krafsur, E. S. 1993. Allozyme variation in stable flies (Diptera: Muscidae). Biochem. Genet. 31: 231-240.

Lehane, M. J., and T. S. Mail. 1985. Determining the age of adult male and female Glossina morsitans using a new technique. Ecol. Entomol. 10: 219-224.

Lehane, M. J., J. Chadwick, M. A. Howe, and T. S. Mail. 1986. Improvements in the pteridine method for determining age in the adult male and female stable fly Stomoxys calcitrans (Diptera: Muscidae). J. Econ. Entomol. 79: $1714-1719$.

Mail, T. S., J. Chadwick, and M. J. Lehane. 1983. Determing the age of adults of Stomoxys calcitrans (L.) (Diptera: Muscidae). Bull. Entomol. Res. 73: 501-525.

Mayer, D. G., and M. G. Atzeni. 1993. Estimation of dispersal distances for Cochliomyia hominovorax (Diptera: Calliphoridae). Environ. Entomol. 22: 368-374.

Murray, M. D. 1995. Influences of vector biology on transmission of arboviruses and outbreaks of disease: the $\mathrm{Cu}$ licoides brevitarsis model. Vet. Microbiol. 46: 91-99.

Parker, R. R. 1916. Dispersion of Musca domestica Linnaeus under city conditions in Montana. J. Econ. Entomol. 9: 325-357.

Parker, F. D., and J. B. Welch. 1991. Influence of attractants on behavior of screwworms (Diptera: Calliphoridae) in a tropical wet forest in Costa Rica. J. Econ. Entomol. 84: $1468-1475$.

Quarterman, K. D., J. W. Kirkpatrick, and W. Mathis. 1954a. Fly dispersal in a rural area near Savannah, Georgia. J. Econ. Entomol. 47: 413-419.

Quarterman, K. D., W. Mathis, and J. W. Kirkpatrick. 1954b. Urban fly dispersal in the area of Savannah, Georgia. J. Econ. Entomol. 47: 405-412.

Riley, J. R. 1975. Collective orientation of night-flying insects. Nature (Lond.) 253: 113-114.

Riley, J. R. 1992. A millimetric radar to study the flight of small insects. Electronics Commun. Eng. J. 4: 43-48.

Riley, J. R., and D. R. Reynolds. 1979. Radar-based studies of the migratory flight of grasshoppers in the middle Niger area of Mali. Proc. R. Soc. B 204: 67-82.

Sayer, H. J. 1962. The desert locust and tropical convergence. Nature (Lond.) 194: 330-336.

Scholl, P. J. 1980. A technique for physiologically age-grading female stable flies, Stomoxys calcitrans (L.). Univ. Nebr. IANR Res. Bull. 298.

Sellers, R.F. 1980. Weather, host and vector-their interplay in the spread of insect-borne animal virus diseases. J. Hyg. 85: 65-102.

Service, M. W. 1981. Sampling methods for adults, pp. 287 296. In Marshall Laird [ed.], Blackflies: the future for biological methods in integrated control. Academic, New York. 
Service, M. W. 1997. Mosquito (Diptera: Culicidae) dispersal-the long and short of it. J. Med. Entomol. 34: $579-588$.

Shemanchuk, J. A. 1987. Host-seeking behavior and host preference of Simulium arcticum, pp. 250-260. In Ke Chung Kim and Richard W. Merritt [eds.], Black flies: ecology, population management, and annotated world list. Pennsylvania State University, University Park, PA.

Shields, E. J. 1999. Remote piloted vehicles (RPV) as sampling platforms for biota in the lower atmosphere. In $\mathbf{M}$. Irwin and D. Aylor [eds.], Aerial dispersal of pests, diseases and their natural enemies: implications for the development and deployment of integrated pest management strategies. Thomas Say Publications. Entomological Society of America, Lanham, MD.

Simmons, S. W., and W. E. Dove. 1941. Breeding places of the stablefly or "dog fly" Stomoxys calcitrans (L.) in northwestern Florida. J. Econ. Entomol. 34: 457-462.

Southwood, T.R.E. 1962. Migration of terrestial arthropods in relation to habitat. Biol. Rev. 37: 171-214.

Szalanski, A. L., D. B. Taylor, and R. D. Peterson II. 1996. Population genetics and gene variation of stable fly populations (Diptera: Muscidae) in Nebraska. J. Med. Entomol. 33: 413-420.

Taylor, L. R. 1974. Insect migration, flight periodicity and the boundary layer. J. Anim. Ecol. 43: 225-238.

Waldbillig, R. C. 1968. Color vision of the female stable fly, Stomoxys calcitrans. Ann. Entomol. Soc. Am. 61: 789-791.

Warnes, M. L., and L. H. Finlayson. 1985. Responses of the stable fly, Stomoxys calcitrans (L.) (Diptera: Muscidae), to carbon dioxide and host odours. I. Activation. Bull Entomol. Res. 75: 519-527.

Webster, F. M. 1903. The diffusion of insects in North America. Psyche 10: 47-58.
Wenk, P. 1981. Bionomics of adult blackflies, pp. 259-279. In Marshall Laird [ed.], Blackflies: the future for biological methods in integrated control. Academic, New York.

Wieman, G. A., J. B. Campbell, J. A. Deshazer, and I. L. Berry. 1992. Effect of stable flies (Diptera: Muscidae) and heat stress on weight gain and feed efficiency of feeder cattle. J. Econ. Entomol. 85: 1835-1842.

Williams, D. F. 1973. Sticky traps for sampling populations of Stomoxys calcitrans. J. Econ. Entomol. 66: 1279-1280.

Williams, D. F., A. J. Rogers, P. Hester, J. Ruff, and R. Levy. 1980. Preferred breeding media of the stable fly, Stomoxys calcitrans, in northwestern Florida. Mosq. News 40: 276-279.

Westbrook, J. K., and W. W. Wolf. 1998. Migratory flights of bollworms, Helicoverpa zea (Boddie), indicated by doppler weather radar, pp. 354-355. In Proceedings of the American Meteorological Society, 13th Conference on biometeorology and aerobiology. American Meteorological Society, Albuquerque, NM.

Wolf, W. W., J. K. Westbrook, J. R. Raulston, S. D. Pair, and S. E. Hobbs. 1990. Recent airborne radar observations of migrant pests in the United States. Philos. Trans. R. Soc. Lond. B 328: 619-630.

Wolf, W. W., J. K. Westbrook, J. R. Raulston, S. D. Pair, and P. D. Lingren. 1994. Radar detection of ascent of Helicoverpa zea (Lepidoptera: Noctuidae) moths from corn in the Lower Rio Grande Valley of Texas. In N. N. Barthakur [ed.], Proceedings, 13th International Congress on Biometeorology, Calgary, Canada, 12-18 September 1993. American Meteorological Society, Boston, MA.

Received for publication 3 December 1998; accepted 29 April 